\title{
Creativity, Symbiosis and Intelligence: The Practice and Optimization Strategy of Urban Community Art in Hong Kong and Shenzhen
}

\author{
Che Xuesen ${ }^{1, *}$ \\ ${ }^{l}$ Cultural and Religious Studies Department, The Chinese University of Hong Kong, Shatin, New Territories, Hong \\ Kong, China \\ ${ }^{*}$ Corresponding author. Email: xuesen0215@163.com
}

\begin{abstract}
Urban community art is a new form of public art, which is a public space that combines the real life conditions of urban community residents and the actual participation of residents. The development and practice of urban community art not only promotes the times and history, but also includes the spontaneous wishes of artists. With the rapid development of the current creative industries, it also covers the economic goals of local governments. However, the purity of art is always the result of its development. Therefore, how to better integrate and coexist between public art and urban communities is the current issue of urban community art development. This article takes Hong KongShenzhen urban community art practice in the context of creative industries as an example to discuss the practice and optimization strategy of urban community art, and aims to point out the direction for the future development of contemporary urban community art.
\end{abstract}

Keywords: Urban community art, Hong Kong, Shenzhen, creative industries, post-epidemic era

\section{INTRODUCTION}

According to the American sociologist Robert E. Prak, a community is a collection of people and organisational systems, and Pierre Bourdieu has pointed out that the formation of a community is not only based on a common way of being, but also on its understanding of that way of being [1]. As a new form of public space, community art is closely related to the lives of the public, and aims to explore how to meet the living and cultural needs of the public and create a community spirit through art, thus achieving a state of 'symbiosis' between art and community development [2]. In harmony with urban development, community art may on the one hand reflect the tendencies of the local government's governance and cultural policies, and on the other hand may suggest a conflict of ideas within the art world, which can be understood as a practical attempt by artists to participate in society through various art forms. Overall, community art can bring a useful perspective and experimentation to the sustainable development of urban communities.

Asia has undergone disruptive changes in demography, economy and urban development over the past few decades, and among these urban changes is the involvement of community art in the process of urbanisation. Urbanisation is undoubtedly a key component of the leapfrogging of urban economies and the modernisation of cities in many Asian countries in the 21 st century. In China, while increasing urbanisation has always been a political strategy for urban development, community art has played an increasingly important role in the process of urban transformation, not only in the cultural role of transmitting and disseminating urban culture, but also in the economic role of promoting economic development and presenting the city's image. For this reason, Shenzhen and Hong Kong have been chosen as representative cities for the case study. On the one hand, Shenzhen and Hong Kong as modern creative cities have pioneering and creative achievements in the practice of community art, creating a positive impact on the sustainable development of the cities; on the other hand, as the two cities practise two very different political systems, and the different political systems may have different effects on the practice of community art. This paper is concerned with the question of exploring what kinds of initiatives have been used in the practice of urban community arts in Shenzhen and Hong Kong. What impact have these initiatives had on the process of urban development, and what problems and dilemmas have 
they generated? Finally, the paper will propose strategies for optimising urban community art in Hong Kong and Shenzhen in the light of the current context.

\section{CONCEPTUAL IMPLICATIONS OF URBAN COMMUNITY ART}

From a sociological point of view, urban communities are the result of the socio-spatial development of a real society combined by urban buildings and constituted by the relationship between urban residents living in the city [3]. Some scholars consider urban communities as social communities with regional ties formed by residents in a certain living space in the city. From a planning perspective, an urban community is an urban territory that is gradually cultivated in the course of the daily life of its inhabitants and has more frequent social interactions within a certain territorial unit [4]. In the context of the current situation of Chinese cities, this paper argues that an urban community is a territorial sphere composed of a group of people who share certain cultural, customary, or developmental goals and who are spatially clustered together. It contains both a physical territory and a spiritual culture. In the Chinese context, urban communities do not necessarily have administrative functions, but their territorial boundaries are within the jurisdiction of community neighbourhood committees, such as urban villages, creative parks, unitary communities, etc.

In terms of the historical lineage of public art, the concept of community art began in the 1960s in the West, usually with artists initiating leadership and planning, leading community residents to collaborate in an artistic co-creation [5]. It emphasises the participation of the community and focuses on the community's unique community relations, cultural identity and public aspirations, and sees art as a means of intervening in urban space with the aim of improving the community economy, improving the living environment and reshaping the community's spiritual culture [6]. As it stands now, urban community art is an emerging art form, a governance strategy that integrates art into the public space of the city and generates interesting responses and interactions with the daily lives of community residents. In short, urban community art is a popular contemporary form of artistic practice and is becoming an important 'cultural powerhouse' for urban regeneration and sustainable urban development.

\section{THE CASES STUDIES OF URBAN COMMUNITY ARTS IN HONG KONG AND SHENZHEN IN THE CONTEXT OF CREATIVEINDUSTRIES}

Hong Kong has been promoting community art since the 1980s, but its initial development was sluggish and the lack of core public art to highlight the city was once derided as a cultural desert. The Public Art Programme was launched in 1999 to encourage organisations, companies and individuals to participate in supporting community art creation by collecting outstanding public art from all over Hong Kong and placing it in various types of urban spaces, with a view to fostering a new image of post-industrial Hong Kong. The aim is to change the public perception of Hong Kong from a cultural desert to a cultural city. Several community art projects are particularly notable, such as the Hong Kong Jockey Club Creative Arts Centre, the Cattle Depot Art Village and the Fotan Studios Based on local cultural practices, these projects have revolutionised the cultural landscape of the city from a global perspective, providing practices that can be applied to the sustainable development of urban communities and showcasing the unique charm of Hong Kong's urban communities.

Table 1 The Cases of Urban Community Art Practice in Hong Kong

\begin{tabular}{|c|c|l|}
\hline Project Name & Start Date & \multicolumn{1}{c|}{ Overview } \\
\hline Fotan Studios & 2001 & $\begin{array}{l}\text { Tucked away in an industrial building, the studios is a bridgehead for } \\
\text { Hong Kong's arts and cultural space. The art space is open to the } \\
\text { public free of charge and actively participates in community } \\
\text { interaction and sharing of artistic processes and achievements. }\end{array}$ \\
\hline Cattle Depot Art Village & 2002 & $\begin{array}{l}\text { Formerly a cattle quarantine station, it was converted into an art } \\
\text { village in 2001 and is managed by the Hong Kong Government. It is } \\
\text { a Grade III listed historic building with a strong folk art atmosphere } \\
\text { and a strong emphasis on artistic involvement in community } \\
\text { interaction. }\end{array}$ \\
\hline $\begin{array}{c}\text { Hong Kong Jockey Club } \\
\text { Creative Arts Centre }\end{array}$ & 2008 & $\begin{array}{l}\text { In 2008, the Government allocated funds to launch the Community } \\
\text { Engagement Planning Programme, which provides community } \\
\text { interaction, workshops, institutional training, curatorial In 2008, the } \\
\text { Government funded the Community Engagement Programme to }\end{array}$ \\
\hline
\end{tabular}




\begin{tabular}{|l|l|l|}
\hline & $\begin{array}{l}\text { organize a wide range of community interaction, workshops, } \\
\text { institutional training, curatorial and practical exhibitions. }\end{array}$ \\
\hline
\end{tabular}

Since 2003, the cultural and creative industries have been listed as one of the six pillar industries in Hong Kong, and community art has had more opportunities to attract the attention of the public and the government. On the other side of Hong Kong, Shenzhen began to support the development of cultural and creative industries in the 21st century. Also in 2003, Shenzhen introduced the slogan 'Culture as a City', bringing greater freedom and support for community arts to intervene in urban spaces. In recent years, with the mandate and support of the central government, Shenzhen has been particularly focused on promoting the integration of creative industries with urban community art, with a view to expanding the city's influence through artistic transformation. Shenzhen's urban art community is closely related to the city's special characteristics. From its early days as a special city of reform and opening up, with a special status for economic, political and cultural development, to its current reinvention through the cultural and creative industries, these urban development strategies have had a direct and significant impact on community art. Many areas have established themselves or have borrowed from them to create a growing community of artists, gradually forming a supply chain of cultural and creative industries.

Table 2 The Cases of Urban Community Art Practice in Shenzhen

\begin{tabular}{|c|c|l|}
\hline Project Name & Start Date & \multicolumn{1}{|c|}{ Overview } \\
\hline Cattle Depot Art Village & 1989 & $\begin{array}{l}\text { One of the most distinctive and controversial urban villages in } \\
\text { Shenzhen, where the production and sale of commercial oil } \\
\text { paintings and various arts and crafts is the main business. }\end{array}$ \\
\hline $\begin{array}{c}\text { Shenzhen Art Creation } \\
\text { Library }\end{array}$ & 2006 & $\begin{array}{l}\text { A new folk art community, a studio and activity base established } \\
\text { using old factory buildings. Gathers artists from all over the country. } \\
\text { Aims to guide the public to participate in the development process of } \\
\text { Shenzhen art, emphasising the local culture and character of the city. }\end{array}$ \\
\hline OCT-LOFT & 2005 & $\begin{array}{l}\text { A contemporary art centre attached to the Museum of Fine Arts, a } \\
\text { non-spontaneously formed art district is led by the government and } \\
\text { enterprises. It aims to enhance real estate and help strengthen urban } \\
\text { culture and improve public cultural facilities in Shenzhen. }\end{array}$ \\
\hline
\end{tabular}

In recent years, under the guidance of the Guangdong-Hong Kong-Macao Greater Bay Area Plan, Shenzhen and Hong Kong have developed many deeprooted collaborations around cultural and creative industries and community arts. One of the most wellknown is the Shenzhen-Hong Kong Biennale, focusing on architectural art and future urban development, which has now been held for eight years and is favoured by the government, enterprises and individuals. The transformation of community art from a governance policy perspective has brought more humanistic planning and policy support for sustainable urban development, as well as using cultural and creative industries as a way to try to reposition the city's image. In a macro sense, the development plans and visions of the Guangdong-Hong Kong-Macao Greater Bay Area offer more possibilities for dialogue between arts and culture and the city, through the creation of differentiated cultural iconic symbols of Shenzhen and
Hong Kong, a humanistic Bay Area, and an arts capital of Asia. On a micro level, through two-way interaction of policies, a variety of industries such as design and architecture are guided to actively participate in the construction of art in urban communities, giving new life to urban communities through the transformation of environmental landscapes and transforming industrial buildings into artists' workshops or creative spaces, thus achieving sustainable development of urban communities. in February 2016, the Hong Kong and Shenzhen governments jointly signed an agreement to promote cooperation in creative industries, proposing the establishment of a cultural and creative industries platform in Qianhai to promote in-depth cooperation between the design and creative fields of the two places, which has now become a new model for exploring cooperation between the cultural and creative industries of Shenzhen and Hong Kong. 


\section{PROBLEMS AND REFLECTIONS OF URBAN COMMUNITY ARTS PRACTICE}

Although the current urban community arts practice in Hong Kong and Shenzhen is fruitful and developing well, there are still some difficulties at the awareness and implementation levels.

Firstly, the development of many government-led urban community arts industries is problematic in its one-sidedness. Art communities with too many economic factors often lack real artistic flair and value. Many art communities are incorporated into creative industry parks, and although the appearance of the community and hardware facilities are significantly optimised, they are often not what the artist's personality or artistic life requires. The standardised architecture has led to the loss of the naturally occurring community culture and aesthetics, and the overly sophisticated property management has limited the casual and casual living conditions of the people. These cannot be called truly creative and are far removed from the real lives of the community's inhabitants. Urban community art should be based on the original state of the community, inspiring artists to be creative and thus forming a true sense of urban community art.

Secondly, the quality of community participation needs to be improved. From the perspective of community art creation, community organisations hope to gradually guide residents to initiate activities on their own through the organisation of art events [7]. However, community residents are often only performers or participants, and these involvements are external rather than active, and do not allow residents to become co-creators of the arts in their communities. Numerous studies have shown that in most communities in China, the involvement of community residents in affairs is often only a perfunctory cooperation. In today's internet age and the trend towards a younger community, the public is no longer a passive recipient and the practice of art in urban communities needs to encourage public participation. The public needs to be fully mobilised in projects of art practice and guided to delve into the practice. This requires the establishment of an effective public art system that promotes genuine, long-term participation by community residents through a good model of production, consumption and dissemination.

In addition, a long-term management and cooperation mechanism for the development of art in urban communities needs to be established. Art often plays only an embellished role in the construction of urban communities, presenting in fragmented forms, lacking overall planning and long-term cooperation mechanisms, and thus failing to bring its proper value to bear in urban construction. Urban community art practice requires multi-party cooperation, with projects guided by relevant experts and scholars, especially in the promotion of short-term results that require media diversion. The government level needs to create an important awareness of urban community art and play a proper role in guiding and promoting it.

\section{OPYIMISATION STRATEGIES FOR COMMUNITY ARTS IN THE POST- EPIDEMIC ERA}

In the post-epidemic era, the community is still the main focus of urban construction and development. With the development and replacement of new technologies, the development model of all sectors is gradually changing towards digitalisation and intelligence. The combination of community art and technology will also become an inevitable trend. The future development of urban community art will gradually shift towards cloud-based, intelligent, scenario-based and interactive.

\subsection{Cloud-based}

Although cloud-based is an emergency response to various art activities during the epidemic, there is also a certain inevitability to the integration of art and technology. This is confirmed by the new aesthetic experience reaped from the cloudification of community art. With this attempt at practice, cloud-based community art will also become the norm in the future. Community art should rely on the community cloud platform, with the aim of better building community art culture, making the dissemination of community art content more timely and comprehensive, forming a new pattern of online cloud tours, offline zoning exhibitions, and promoting art deeper into the lives of residents.

\subsection{Intelligence}

The goal of modern urban development is to achieve urban intelligence, and communities, as the main place where people live and work, are bound to become an important space for intelligent development. Nowadays, intelligent communities have become the current development trend of modern urban housing, and urban community art should allow art to be integrated into the modern living environment, supporting facilities and property services. In short, the intelligence of community art is to allow urban residents to feel the convenience brought by technology while enriching their spiritual lives.

\subsection{Scenario-based}

In fact, the intelligence of community art is a reflection of smart city construction, allowing residents to experience an elegant culture through the construction of new living scenes. Many governments and enterprises are trying to design various scene-based 
applications, such as environmental protection projects, community living services and public space management. The scene-setting of community art is building a higher level of artistic and cultural interaction. Scene based community art consists of the cultural atmosphere in the community's daily life environment, with the core being the preservation and revitalisation of the community art and cultural landscape and the construction of art spaces. This means that all residents, from children to the elderly, are provided with artistic public services to create a more positive form of artistic perception, and that new scenes of urban community art are constructed through intelligent technology and services [8].

\subsection{Interactivity}

The interactivity of community art is the expression of community public art concepts through various media and art forms to achieve the effect of mutual influence between works and residents and resident participation [9]. Interaction reflects a humane respect. The interactivity of community art is reflected in the process of community residents' participation and experience of community art. Community residents test the effects of community artworks by interacting, communicating and experiencing them. Because of their diverse characteristics, community art works accept different levels of aesthetic demand through community art, meet the participation needs of community residents, achieve communication and connection between art and residents, and thus become true public art. Through diverse artistic means such as community landscape installations, sculptures, multimedia images, light effects and architecture, urban community art can realise interactive experiences that residents can see, swim, smell, touch and even taste, achieving a perfect fusion of technology and art.

\section{CONCLUSION}

It is undeniable that the initial community art was an extension of the artists' participation and integration into the community. In the later stages of development, its artistic nature was amplified and its economic and cultural nature gradually came to the fore, which was then promoted by relevant institutions, governments and enterprises to generate creative industries, eventually developing into an art form and space that carries the functions of urban communities based on creative industries [10]. The development of art in urban communities in Hong Kong and Shenzhen depends on the integration of art and the city. Regardless of the rise and fall of the city, art can flourish or sink. There is no clear direction for the development of urban community art in the light of various factors. In today's context, in addition to maintaining artistic purity, urban community art should also adapt to the current economic development conditions in order to achieve sustainable development of urban communities.

\section{REFERENCES}

[1] Grenfell, M., Ebrary, I. (2012). Pierre Bourdieu: key concepts. French Studies, 64(4):517-518.

[2] Hal Foster. (2002). Artist as Enthnologer? in Global Vision: towards a New Internationalism in the Visual Arts. London: Kala Press. pp.12-19.

[3] Nicolas Bourriau. (2002). Relational Aesthetics. Les presses du reel. pp.26.

[4] Clifford Geertz. (1983). Local knowledge: Further Essays in Interpretive Anthropology. New York: Basic Books Inc.pp.68.

[5] Randolph, T., Hester, Jeffrey Hou, Laura, J., Lawson, E. (2017). Design as Democracy: Techniques for Collective Creativity. The United States of America: Island Press. pp. 344.

[6] Antti Pirhonen, Pertti Saariluoma, Hannakaisa Isomaki, Chris Roast. (2005) Future Interaction Design. Springer. pp.28.

[7] Rockwood, K. (2004). Lending a helping eye: artists in residence at a memory clinic. The Lancet Neurology, 3(2): 119-123.

[8] Eckhoff, A. (2011). Art experiments: introducing an artist-in-residence programme in early childhood education. Early Child Development and Care, 181(3):371-385.

[9] Sasajima, Hideaki. (2013). From red light district to art district: Creative city projects in Yokohama's Kogane-cho neighborhood. Cities, 33:77-85.

[10] Hartley, H. (2018). Cultural policy and collaboration in Seoul's Mullae art district. GEOFORUM. 11:177-188. 